Journal of Social Sciences 2 (4): 104-107, 2006

ISSN 1549-3652

(C) 2006 Science Publications

\title{
The International Law Classification as an Understanding of the Built of International Law
}

\author{
Mohammad Mousa Al-Swelmeen \\ Al-Balqa Applied University, Al-salt, Jordan
}

\begin{abstract}
Talking about the structure of international law as part of interior system, for accuracy and determined its rules we have to classify the international law rules completely. The main problems which face the international law rules for the purpose of searching the modern international law's structure are being included in the similarity and the classification of regularity side, to permute clearness a group of interior organization processes for international law system. Besides the most benefits classification will be built on an understanding on how will join law as are built by the understood classification, according there is reaction of standard unit to determine it.
\end{abstract}

Key words: International law rules, law structures, interior organization processes

\section{INTRODUCTION}

In many last searching has talked about the international law built due to standard which it serves us by the classification of in law rules the standard group of containing the in law is built on the basic of the rules unity and No. of pursues and their filed who arrange the international relation beside of various society foundations for us in not suit to speak the international law built due to various standards.

Since the built consider as the first description of the system in general also concern as builder of the relation must apply one law far self arrange, to all international law systems.

Classification of international law: The most full and detail classification which inform of important evidences in F.B.A Fcilinco work and E.E Lokoshka, in spite of international law rules case in respect of its most important consider a subject care far most editors[1,2].

Let us stop a little on the basic classification sides of this problem. Firstly the standard group of international law rules are different mostly between editors, according the same classification maybe divided by two searchers are realized from various rules of division.

Thus, the international law rules divided to international, local and district, take care by editors in response of various standard (Work filed E. E Lokoshka B.E Surfeit and others) (personals difference and address A.A. Ushkouf B.A. Faslika). There are several discrepancies of classification illustration level have indicated before[2,4]. Thus, someeditors like to divide the international law rules into two fair sections due to international and local standards " B.E Soufrofa N. Oshkof and others N. Oshkof is the one who divides the international law rules into international and local ones. Indicating his role of the last books that the individual rules which illustrate the personal behavior as a certain individual event[5,9]. However, the classification of international law rules in respect of wide activity, which was suggested by " B.A. Facilinko " described as high level of discrimination.

The world divides the Indicated standard for international law rules into international, religious and groups.

Conceptually and overlooking the indicated discrepancies in the ways of describing the classification of the international law rules according to activity range, the specific classification of the international, religious, local and the mutual relationships can be practically and exclusively defined by various editors. Meanwhile this proves that the similar classification could be neutral and legal from our point of view. Thus, the international rules which divided into principals ' rules (which counted for the multiple implementation of the rules that are approved internationally, have different sides and are inclusive character) which form the general international rule. All or most government admitted that and generally it can be specified or cancelled by international community and distributed to all cooperated specialized who deal with the international law and its considered characterized with obligated general law.

According to some editors, the unity of the rules could be essential for the present international law.

These rules can be associated with regional, legal and international principals and its executions can be determined according to each region or area. For example, the expired rule in mutual relationships between the country members of the league of Arab States who signed the Mutual Arab Defense Agreement

Corresponding Author: Mohammad Mousa Al-Swelmeen, Al-Balqa Applied University, Al-salt, Jordan, Tel: 00962-5-3533625, Fax: 00962-5-3533625 
and the Cooperated Economy Agreement on 13/4/1950.)

Finally, the affect of the local rules, which considered more than behavior restrictive precepts, comparing with the international and regional ones under narrow rang in international society (as local rules which mentioned in the statement of the continental flat area of Belteque countries on 23/11/1968). Some researchers stats that the most distinguished character for the present international law is summarized in its concern of the privacy of each country's statue and the country's significant relationships [8].

The classification of the international law rules within its activities and with showing the privacies of these rules whereas content and functional side, it won't be considered from our point of view, as one of the possibilities for dividing the structure of the international law, because it does not respond to any questions about: what are its relationships? And what are the preferred characteristics of the rule that will become its relationships ' rule?

Meanwhile, it shows that there are radical features for elements that allow seeing behind functional and objective characteristics, generally showing the importance of international law structure and determining the unique and vertical relation.

The most common classification of the international law rules is the one that will be generally done according to law (other expressions, according regulations or according to specifying competencies). Thus, naturally its obligatory, prohibitive and inhibitive. The obligatory rules focus on the duties of the cooperative sides and it show ways and methods of affecting these rules. The accepted rules and which set up the specific duties for the involved laws by agreements through cooperation, belong essentially to obligatory rules

However, the prohibitive rules contain forbidden list for either doing particular activities or not. Such as noninterference principal, this forbid forcibly threatening or it may be used for international relations etc.

In addition and regarding to inhibitive rules, it focuses on mutual cooperation principals between the involved authorities and it defines the ways and methods of executing these principal. Pursuing the basic principal of the international law of aircraft and celestial bodies could be opened for researcher and used, by all countries in accordance to the international law.

Without exception, the prohibitive and inhibitive rules are satisfied with its principals. Meanwhile, it imposes and deters every person by the same standards according to international law, forming one general law for cooperation between countries.

Practically, the editors of international law agree to divide the international law rules to normal, agreement and solution principals for international organization based on the nature of resources. (B. A. Facilinco) and the forth set of legal principals which describes the rules and available in the manuals of the international courts, are also included in this classification. Researchers agree to classify the rules according to the level of standard duty and to the features of regular efficiency. In other words, they will classify it according to the basis of law rule and the caution system in international law in to instructing and organizational rules. The rules of (Jose Kojens) are instructing according to international law and it allows separating the content from the subject demands of the in international law rules. Instructing rules can be changed into supplemented rules has the same characteristics [6,7]. Generally, Thelaw provides that the instructing rules considered first class according to the rest of the rules of international law, provided through Vienna agreement 1969 for international law's agreement and the 1986 one for the law of agreement between countries and international organizations or between the international organizations itself. In the case of breaching, the instructing rules there will be general legal responsibilities against to each country have lawsuits against criminals $[3,8]$.

The rules of the international law organizations can be neutralized by contracts between to countries or more. the organizations rules has a complete authority rights which have been confirmed by set of documents particularly in the report of the international court of the United Nation in regards to the continental flat area of North Sea on 20/2/1969 and Vienna agreement for the signed agreements on 23/8/1969 page (9) of the league of Arab states ' Charter. While international court witness facts, it is possible not only to increase our confidence in it, but also to stop completely by the cooperative relations, which were accepted by both sides.

Therefore and practically, researchers have agreed to divide the international law rules based on the nature of its resources, but legally on reaching to the nature of classifying the rules based on the content of the standard description and the characteristics of its multiple functions, which will lead to radical variation between them.

Thus and based on the indicated standard, the international law rules are divided into two classifies ; the first one is materialistic (primary) and the second one is procedural (secondary). Materialistic rules set forms and principals of the international law, meanwhile the procedural rules determine the directions of handling problems peacefully such as, negotiations, law Consultations Groups, International Organizations' Members Institutions and other. On the other hand, the system of taking the obligation measures will impose a legal International prohibition against the resistance country. 
The procedural description carries on an important part, which has been confirmed by Vienna agreement in1969, which contains of the rights of the organized International agreement for activating, exporting and executing those agreements. And according to the international organization rules and laws " legal Principals for Right " the priority law, which associated with generalized, stated that no one can rule himself in his personal matters.

B. A. Falcilinco suggests one far-reaching category for materialistic and procedural rules, indicating the dividing of the materialistic rules into specified rules, compensated rules and maintaining rules, all which based on its organized function characteristics. While the procedural rules was divided into harmonized and obligated ones, Therefore, researcher will confirm that the harmonized rules take priority and leading role through the international law rules And he will often submit the international methods same as one method for procedural organization [2.9].

There is another opinion according to the procedural rule (secondary) that N. A. Oshko is holding into it. He describes the secondary rules as the one that is executing when resisting the subjects of the primary rules. Besides, it will result negative lawful appendings, (the similar definition for the secondary rules has been implemented by the Committee of international law which belongs to United Nation Organization when they were working on the project of the texts which related to the responsibilities of the countries.) for example, the secondary rules will be internationally in charge of the international law resistance activities. Therefore the secondary rules can be described as an organization and maintenance of the laws.

Meanwhile and regarding to the procedural rules we can divide the editors theories, which have been recognized widely, into two kinds, the first rule is to organize the construction procedure, but the second rules is to achieve the international law (B. A. facilinco and Y. Y. Lockshock) $[2,5]$. The right understanding of the international legal procedural rules will respond to international relation requirements. These days executing procedural rules happened to be rarely done in meaning of its obligation, but in regards to its significant solutions for international conflicts, it can be used organizing various daily cases (not the hard ones) which associated with the mutual cooperation of the international law members.

There is also a set of various categories for international legal rules through the international legal principals. These categories are based on content, place and system regarding to (Y. Y. Lockshock). But (B. A. facilinco), classifies these rules into the following bases:

A. The alignment of the international laws to the secondary system and the international law systems.
B. Reaching out to the highest level of international legal rules.

C. The organizational tendency of those rules and its constant efficiency characteristics.

D. Official legal signs.

E. The implementation of these rules.

Generally, analyzing the integral classifications will allow us to solve many critical cases.

First: The nature of the integral classifications of the international legal rules will clear the way for displaying a group of internal system for the present international law.

Secondly: Analyzing those classifications will allow us to reach out to a whole set of conclusions, which have relation with the structure of international law and express he subjective arrangements of the system.

So, all available classifications for the law rules can be divided into two categories. the first category could be included with categories that have related standards in showing the most important descriptions for international legal rules. While the other category, could be included with categories that depend on the formal features of the international law.

We believe that the second classifications has a relative of the (system description) international law.

Rule system. The classifications of the first kind, in our Opinion and according to its nature, it can't be as apart of organic built which seem few of foundations ' built for a modern) international law.

The evidence on that, according to our view concerning that event had spoken about all classifications of descriptions, indicated to that, it has one mutual factor, by concerning itself as one element foundation for general international law principle. Thus, the original foundation which consider an independent, more than importance of international law rules by mean of the law.

According to work filed, shifting to the side of the secondary international law rules, reaching the level of international law and the location and subjects etc. All those principles are the most important international rules groups (Especially the material which control on the secondary system to direct the way of arranging the international law by both meaning quality $\&$ quantity). Finally, it determines the specialist of the modern procedures rules especially control on the harmonize rules with its role as a pant for organizing cases and problems, which appear during conflict processes between the international society members. Thus and by taking into consideration all what have mentioned above, we can assume the content classifications of international law rules appear an individual characteristics structure of international law $\mathrm{m}$ appended a progressive degrees system, In alternative relation for whole and partial. From this point we have to understand progressive degrees not be formal meaning of law improvement but by objective meaning. 
In this way the specialist of understanding modern international law maybe illustrate within the political content for international law at the same time as one part. Actually, it has an unique element to make laws group, in addition, the description of this foundational built relation (Transaction laws) must be publishing as maximum cases in our opinion, as this transaction should be published in any side of thousands groups modern international law rules. The thing of these international law rules made the goals clearly of content.

The material phenomenon, which serves the int. law rules foundation, can be determined within the characteristics of the modern int. laws arrangements and within the normal foundation principles.

If the int. law can be active sufficiently, it will accept biggest concerning of achieving its goals (as in complex systems of applying laws in reactivate effect. which determined the formal of the two systems in general). The role of the int. law does not come by the way of increasing the recommendation on states but within determined goals and responsibility field by more clearness, the foundation of int. laws has a big role to reflect consciousness.

Replacement of lawness of int. relation and its national general benefit and to be fixed the main goals for International Corporation all of that we can say that the built thought and the social goals be in deeply meaning modern int. law concerning these value thought joins and progression degree be apart of int. laws rules classifications according to rules appearance (quality).

\section{REFERENCES}

1. Locshenco, E.E., 1989. Int. law general part in 1996, pp: 98, Philosophy Dictionary 1981, pp: 200. Int laws book 7 pant T.A. 1989, pp: 268 subject page 103,105,107,11,112,121.

2. Fasilince, B.A., 1988. Int. law principles K. High school. Pp: 228, 268, subject 229, 233, 230, 235, 238, $260,247$.

3. Souferofa, B.E., 1975. Int. of local laws principles. An assistant teacher of law collage.

4. Anoshcrof, 1996. Understanding and expression of int. law. Pp: 7.

5. Hamdan, Y.A.H.S., 1989. Normal and harmonies principle. Assistant teacher of law's science, pp: 15.

6. Anonymous, 1969. The decision relation to the continental surface of the North Sea. Pp: 44.

7. Merinouf, B.F., 1980. Int. law, laws \& authorizing principle.

8. Boulenino, S.B., 1996. Law's creation in rush a federal union. Pp: 31.

9. Dr. A.W. al-Naser, International relations. Moraco. 